\title{
FDA Classified Non-traditional Sterilization Method
}

National Cancer Institute

\section{Source}

National Cancer Institute. FDA Classified Non-traditional Sterilization Method. NCI

Thesaurus. Code C106133.

Sterilization methods that do not have a long history of safe and effective use and for which there are no FDA-recognized standards, but for which published information on validation of these methods exists and for which FDA has previously evaluated data as part of a QS evaluation and determined the methods to be adequate. 